\title{
Protective effect of the combinations of glycyrrhizic, ferulic and cinnamic acid pretreatment on myocardial ischemia-reperfusion injury in rats
}

\author{
YUQIN GAO ${ }^{1,2}$, JIPING HAO ${ }^{1}$, HONGKAO ZHANG $^{3}$, GUOQIANG QIAN $^{4}$, \\ RENWANG JIANG ${ }^{5}$, JING HU ${ }^{2}$, JIANING WANG ${ }^{5}$, ZHANG LEI $^{5}$ and GUOPING ZHAO ${ }^{2}$ \\ ${ }^{1}$ Department of Cardiology, Ninth Affiliated Hospital of the Medical College of Xi'an Jiaotong University \\ and Railway Central Hospital of Xi'an, Xi'an, Shanxi 710054; ${ }^{2}$ College of Medicine, \\ Jinan University, Guangzhou, Guangdong 510632; ${ }^{3}$ Department of Nursing Science, \\ Huanghuai University, Zhumadian, Henan 463000; ${ }^{4}$ College of Pharmacy, \\ Jinan University, Guangzhou, Guangdong 510632; ${ }^{5}$ Department of Cardiology, Renmin Hospital, \\ Hubei University of Medicine, Shiyan, Hubei 442000, P.R. China
}

Received February 14, 2014; Accepted August 1, 2014

DOI: $10.3892 / \mathrm{etm} .2014 .2134$

\begin{abstract}
The aim of this study was to find an effective drug cocktail pretreatment to protect myocardial tissue of the heart from ischemia-reperfusion (I/R) injury. The mechanisms underlying the effects of the drug cocktail were subsequently explored in order to expand the application of Dang-gui-si-ni-tang (DGSN), a Traditional Chinese Medicine. The active components of DGSN in the serum following oral administration were investigated using high-performance liquid chromatography. The activity of superoxide dismutase (SOD) and malondialdehyde (MDA) levels were then analyzed to show the effect of the active components in the treatment of myocardial I/R injury. An L16 $\left(4^{4}\right)$ orthogonal experiment was utilized to determine the most effective cocktail mix and the mechanism underlying the effect of this mix on myocardial I/R injury was investigated. It was observed that FCG, a mixture of glycyrrhizic $(50 \mathrm{mg} / \mathrm{kg})$, cinnamic $(200 \mathrm{mg} / \mathrm{kg})$ and ferulic $(300 \mathrm{mg} / \mathrm{kg}$ ) acid, was the optimal drug cocktail present in DGSN. This was absorbed into the blood following
\end{abstract}

Correspondence to: Dr Guoping Zhao, College of Medicine, Jinan University, 601 Huangpu Dadao Xi, Guangzhou, Guangdong 510632, P.R. China

E-mail: guopingzhao56@163.com

Abbreviations: MDA, malondialdehyde; SOD, superoxide dismutase; TNF $\alpha$, tumor necrosis factor- $\alpha$; IL-1 $\beta$, interleukin- $1 \beta$; IL-6, interleukin-6; ICAM-1, intercellular adhesion molecule 1; $\operatorname{PPAR} \alpha$, peroxisome proliferator-activated receptor $\alpha$; I- $\kappa \mathrm{B} \alpha$, inhibitory- $\kappa \mathrm{B} \alpha$; NF- $\kappa \mathrm{B}$, nuclear factor- $\kappa \mathrm{B}$; CK-MB, MB-isoenzyme of creatine kinase; DGSN, Dang-gui-si-ni-tang

Key words: ischemia-reperfusion cocktail, ferulic acid, cinnamic acid, glycyrrhizic acid oral administration and was shown to decrease MDA levels and increase the activity of SOD. In conclusion, the findings suggest that FCG, a combination of active ingredients in the DGSN decoction, can be absorbed into the blood and protect the myocardium from I/R injury.

\section{Introduction}

Ischemic heart disease is one of the most common causes of mortality in the world (1). Following acute coronary occlusion with the threat of myocardial infarction, the current cardiological protocol for acute myocardial infarction is rapid reperfusion. Although reperfusion is required to salvage ischemic tissue, it is associated with cellular damage due to the activation of deleterious signaling cascades (2). A number of studies have shown that ischemic preconditioning is an innate protective strategy that markedly reduces ischemia-reperfusion (I/R) injury (3-5). This, however, is not acceptable as a clinical tool due to practical difficulties associated with the local induction of cardiac ischemia, ethical reasons and the fact that the index ischemic episode is often unpredictable. Therefore, it is necessary to search for a novel approach, one that is more suitable for the clinical scenario.

Pharmacological preconditioning can simulate ischemic preconditioning and markedly reduce injury from I/R. Furthermore, this method is associated with an easy execution. To date, numerous drugs that can prevent the myocardium from I/R injury (6-8) are available.

Dang-gui-si-ni-tang (DGSN) decoction is a classical formula in Traditional Chinese Medicine that originated from a medical textbook known as the 'Treatise on Cold-Induced Febrile Diseases', which dates back to 200 C.E. DGSN is treatment for coronary heart disease. Studies have indicated that glycyrrhizic, ferulic and cinnamic acids are the active components in the DGSN decoction (9-11). In addition, the majority of these studies have reported that glycyrrhizic, cinnamic and ferulic acids have a protective effect against I/R 
injury. The protective mechanism of glycyrrhizic acid on I/R injury was found to be associated with its antioxidant (12-14), anti-inflammatory (15) and anti-apoptosis effects (16), as well as its inhibition of lipid peroxide (17). Cinnamic acid exerts cytoprotection by acting as an antioxidant and anti-inflammatory agent (18-20). Ferulic acid can also inhibit oxidative stress, inflammation (21) and cell apoptosis (22) and modulate mitochondrial function (23). These mechanisms are associated with the alleviation of I/R injury. Considering that glycyrrhizic, cinnamic and ferulic acids are major components of the DGSN decoction, which is used to treat coronary heart diseases (9-11), we hypothesized that different combinations of the active ingredients in the DGSN decoction may also have a similar therapeutic effect.

The aims of this study were fourfold. Firstly, we aimed to verify whether glycyrrhizic, cinnamic and ferulic acids could be absorbed into the serum of rats following oral administration of the DGSN decoction. We then aimed to investigate the effects of pretreament with glycyrrhizic, cinnamic and ferulic acids and peoniflorin on superoxide dismutase (SOD) activity and malondialdehyde (MDA) levels in the myocardium of a rat model of I/R injury, and to utilize an L16 $\left(4^{4}\right)$ orthogonal experiment to find the optimal active combination. Thirdly, we aimed to investigate the protective effects of the optimal active combination pretreatment against myocardial I/R injury in rats, and, finally, to investigate whether the protective effects were associated with tumor necrosis factor- $\alpha(\mathrm{TNF} \alpha)$, interleukin (IL)-1 $\beta$, IL- 6 and the nuclear factor- $\kappa \mathrm{B}(\mathrm{NF}-\kappa \mathrm{B}) \mathrm{p} 65$ and peroxisome proliferator-activated $\alpha(\operatorname{PPAR} \alpha)$ signaling pathways.

\section{Materials and methods}

Materials. Male Sprague Dawley (SD) rats weighing 280-400 g were purchased from the Guangdong Experimental Animal Center (License no. SCXK 2008-0002; Guangzhou, China). The animals were maintained in individual cages at room temperature under light-controlled conditions. The rats were provided with food and water ad libitum. All animal procedures were in accordance with the Regulations of Experimental Animal Administration issued by the State Committee of Science and Technology of the People's Republic of China on November 14, 1988. Glycyrrhizic acid (purity >98\%), ferulic acid (purity $>99 \%$ ), peoniflorin (purity $>98 \%$ ) and cinnamic acid (purity $>99 \%$ ) were purchased from Nanjing Zelang Medical Technology Co., Ltd. (Nanjing, China). The following primary antibodies, which were obtained from Santa Cruz Biotechnology, Inc. (Santa Cruz, CA, USA) unless stated, were used: Anti-phosphorylated (phospho)-Akt1/2 [serine (Ser)473] (cat. no. 9271; Cell Signaling Technology, Inc. Danvers, MA, USA), anti-inhibitory(I)- $\kappa \mathrm{B} \alpha$ (cat. no. SC-101712),

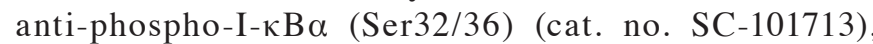

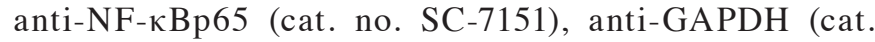
no. SC-25778) and anti-PPAR $\alpha$ (cat. no. SC-9000). Horseradish peroxidase-conjugated goat anti-rabbit immunoglobulin $\mathrm{G}$ (IgG; Heavy and Light chain) was purchased from Beijing Biosynthesis Biotechnology Co., Ltd. (Beijing, China). SOD, MDA, TNF $\alpha$ ELISA, IL-1 $\beta$ ELISA and intercellular adhesion molecule-1 (ICAM-1) ELISA test kits, as well as pentobarbital and 2,3,5-triphenyltetrazolium chloride (TTC),
Table I. Program of gradient elution.

\begin{tabular}{lcc}
\hline $\begin{array}{l}\text { Time, } \\
\min \end{array}$ & $\begin{array}{c}\Phi \text { (acetonitrile), } \\
\%\end{array}$ & $\begin{array}{c}(0.5 \% \text { aqueous acetic acid), } \\
\%\end{array}$ \\
\hline $0-12$ & 15 & 85 \\
$12-30$ & 50 & 50 \\
$30-33$ & 15 & 85 \\
$33-38$ & 15 & 85 \\
\hline
\end{tabular}

were purchased from Nanjing Jiancheng Technology Co., Ltd. (Nanjing, China). Enhanced chemiluminescence diagnostic, bicinchoninic acid (BCA) protein assay and nucleoprotein and plasmosin extraction kits were purchased from Nanjing KeyGen Biotech. Co., Ltd. (Nanjing, China).

Preparation of the DGSN decoction. The ratio of Angelica sinensis, Radix Paeonia, Ramulus Cinnamomi, Herba Asari Mandshurici, Radix Glycyrrhizae, Medulla Tetrapanacis and Fructus Jujubae in DGSN was 4:3:3:1:2:2:2. The DGSN was purchased from the First Affiliated Hospital of Guangzhou University of Traditional Chinese Medicine (Guangzhou, China). The DGSN was boiled twice in distilled water $(1: 12, \mathrm{w} / \mathrm{v})$ for $30 \mathrm{~min}$. The blended supernatants were then condensed to a concentration of $1 \mathrm{~g}$ crude $\mathrm{drug} / \mathrm{ml}$. Liquid extraction $(500 \mu \mathrm{l})$ was mixed with $2 \mathrm{ml}$ blank rat serum. The mixed liquid was acidified with $20 \mu \mathrm{l}$ acetic acid and extracted with $8 \mathrm{ml} \mathrm{n}$-butanol. Subsequent to centrifugation at $400 \mathrm{x} \mathrm{g}$ for $20 \mathrm{~min}$ at $4-6^{\circ} \mathrm{C}$, the organic phase was transferred into an empty tube and evaporated to dryness under nitrogen at $40^{\circ} \mathrm{C}$. The residue was dissolved in $1 \mathrm{ml}$ methanol and filtered (0.22 $\mu \mathrm{m}$; Millipore, Billerica, MA, USA), and an aliquot $(20 \mu \mathrm{l})$ was then injected into the high-performance liquid chromatography (HPLC) system.

Preparation of reference compounds and HPLC analysis. The purity of the glycyrrhizic, cinnamic and ferulic acids and peoniflorin was $>98 \%$. The chromatographic analysis was performed on an Agilent 1200 system (Agilent Technologies, Palo Alto, CA, USA), which was composed of a quaternary gradient pump, an auto sampler, a Cosmosil C-18 column (5 $\mu \mathrm{M}$ particle, $250 \times 4.6 \mathrm{~mm}$ ) and an ultraviolet detector. The mobile phase was acetonitrile- $0.5 \%$ aqueous acetic acid. The analysis was performed at a flow-rate of $1.0 \mathrm{ml} / \mathrm{min}$ with detections at 320, 230, 275 and $254 \mathrm{~nm}$. The gradient solvent system is shown in Table I.

All reference compounds were dissolved in dimethyl sulfoxide to afford $50 \mathrm{mmol} / \mathrm{l}$ stock solutions separately. The concentration of mixed standards were as follows (where G, F, $\mathrm{P}$ and $\mathrm{C}$ stand for glycyrrhizic acid, ferulic acid, peoniflorin and cinnamic acid, respectively): Mixed standard 1 (G: $4 \times 10^{-8} \mathrm{~mol} / \mathrm{l}$, F: $2 \times 10^{-8} \mathrm{~mol} / \mathrm{l}, \mathrm{P}: 2 \times 10^{-8} \mathrm{~mol} / \mathrm{l}$ and C: $\left.2 \times 10^{-8} \mathrm{~mol} / \mathrm{l}\right)$; Mixed standard 2 (G: $8 \times 10^{-8} \mathrm{~mol} / \mathrm{l}, \mathrm{F}: 4 \times 10^{-8} \mathrm{~mol} / \mathrm{l}, \mathrm{P}: 4 \times 10^{-8} \mathrm{~mol} / 1$ and C: $\left.4 \times 10^{-5} \mathrm{~mol} / \mathrm{l}\right)$; Mixed standard 3 (G: $1.6 \times 10^{-7} \mathrm{~mol} / \mathrm{l}, \mathrm{F}$ : $8 \times 10^{-8} \mathrm{~mol} / 1$, P: $8 \times 10^{-8} \mathrm{~mol} / 1$ and $\left.\mathrm{C}: 8 \times 10^{-8} \mathrm{~mol} / \mathrm{l}\right)$; Mixed standard 4 (G: $3.2 \times 10^{-7} \mathrm{~mol} / 1, \mathrm{~F}: 1.6 \times 10^{-7} \mathrm{~mol} / 1, \mathrm{P}: 1.6 \times 10^{-7} \mathrm{~mol} / \mathrm{l}$ and C: $\left.1.6 \times 10^{-7} \mathrm{~mol} / \mathrm{l}\right)$; and Mixed standard 5 (G: $6.4 \times 10^{-7} \mathrm{~mol} / \mathrm{l}, \mathrm{F}$ : $3.2 \times 10^{-7} \mathrm{~mol} / 1$, P: $3.2 \times 10^{-7} \mathrm{~mol} / 1$ and $\left.\mathrm{C}: 3.2 \times 10^{-7} \mathrm{~mol} / \mathrm{l}\right)$. The 
Table II. Four levels of the four active components in the orthogonal design.

\begin{tabular}{lcccc}
\hline & Glycyrrhizic acid $(\mathrm{mg} / \mathrm{kg})$ & Ferulic acid $(\mathrm{mg} / \mathrm{kg})$ & Peoniflorin $(\mathrm{mg} / \mathrm{kg})$ & Cinnamic acid $(\mathrm{mg} / \mathrm{kg})$ \\
\cline { 2 - 5 } Level & A & B & C & D \\
\hline 1 & 0 & 0 & 0 & 0 \\
2 & 25 & 200 & 25 & 100 \\
3 & 50 & 300 & 50 & 200 \\
4 & 100 & 400 & 100 & 400 \\
\hline
\end{tabular}

mixed standards were mixed separately with $2 \mathrm{ml}$ blank rat serum, respectively; the mixed liquid was acidified with $20 \mu \mathrm{l}$ acetic acid and extracted with $8 \mathrm{ml}$-butyl alcohol. Following centrifugation at $400 \mathrm{x}$ g for $20 \mathrm{~min}$ at $4-6^{\circ} \mathrm{C}$, the organic phase was transferred into an empty tube and evaporated to dryness under nitrogen at $40^{\circ} \mathrm{C}$. The residue was dissolved in $1 \mathrm{ml}$ methanol and filtered $(0.22 \mathrm{dm}$; Millipore). An aliquot (20 $\mu \mathrm{l}$ ) was then injected into the HPLC system.

Serum sample preparation. The 35 male rats were housed in an environmentally controlled room and divided randomly into seven groups (five rats in each group). The seven groups represented different time periods, i.e. 30, 60, 90, 120, 180, 360 and $540 \mathrm{~min}$ ). The DGSN decoction was orally administered to the rats at a dosage of $20 \mathrm{~g} / \mathrm{kg}$. The abdominal cervical artery was then punctured under pentobarbital sodium anesthesia and the blood $(5 \mathrm{ml})$ was collected. Each rat yielded $2 \mathrm{ml}$ serum. The serum samples were processed according to the same procedure as the standard samples. An aliquot $(20 \mu \mathrm{l})$ was injected into the HPLC system.

Experimental protocols. In the first set of experiments, it was investigated whether the DGSN decoction contained the ferulic acid, peoniflorin, cinnamic acid and glycyrrhizic acid (FPCG) combinations and, if so, whether these active components were absorbed into the blood following oral administration of the DGSN decoction. Animal experiments were then performed based on an $L 16\left(4^{4}\right)$ orthogonal design (24-26), setting four factors with four different levels (Table II).

SD rats were randomly divided into the above 16 groups ( $n=6$ per group). Prior to surgery, the rats were administrated different doses of the GFCP combinations for 5 days (once a day, five doses in total). The last dose was administered $30 \mathrm{~min}$ prior to the surgery.

In the third set of experiments, the SD rats were randomly divided into three groups ( $n=10$ per group). The first group underwent the same procedure as groups II and III, except the suture was passed under the coronary artery without ligation (sham group). In group II, the rats underwent $30 \mathrm{~min}$ ischemia followed by $2 \mathrm{~h}$ reperfusion. In group III, the rats were administered the FCG combination (glycyrrhizic acid, $50 \mathrm{mg} / \mathrm{kg}$; ferulic acid, $300 \mathrm{mg} / \mathrm{kg}$ and cinnamic acid, $200 \mathrm{mg} / \mathrm{kg}$ ) for five days prior to I/R. At the end of the experiments, $4-5 \mathrm{ml}$ blood was obtained. The serum was separated from the blood cells by centrifugation and stored at $-80^{\circ} \mathrm{C}$. For further analysis, the hearts were prepared for infarct size measurement or the tissue was quickly frozen and stored at $-80^{\circ} \mathrm{C}$.
Surgical preparations. The surgical protocol was performed according to methods described previously (27). Briefly, rats were anesthetized with pentobarbital $(50 \mathrm{mg} / \mathrm{kg}$, intraperitoneal), intubated and ventilated with mechanical ventilation (tidal volume, $30 \mathrm{ml} / \mathrm{kg} ; 70$ strokes per min). The rats were placed on heating plates to maintain core temperature within the normal range $\left(37.0-37.6^{\circ} \mathrm{C}\right)$ and the left femoral vein was cannulated to inject the drugs. With the fourth intercostal space opened, the heart was exteriorized and the pericardium was cut. The left anterior descending coronary artery was ligated between the left atrium and the pulmonary outflow tract using a 6-0 silk suture. Successful ligation was verified by regional cyanosis of the myocardial surface and ischemic ST-segment changes in the electrocardiogram. The heart was subsequently replaced in the thoracic cavity, the thoracic cavity was drained of remaining air (to avoid pneumothorax) and the chest was immediately closed. Following occlusion for $30 \mathrm{~min}$, the left anterior descending coronary artery was opened to permit reperfusion for $2 \mathrm{~h}$.

Measurement of area at risk (AAR) and infarct size (IS). Myocardial IS and AAR were determined as described previously (27). Briefly, at the end of reperfusion period, the rat hearts were removed and the aortas were quickly cannulated. Once the coronary artery ligature was tied, the hearts were perfused with Evan's blue at a constant pressure (80 $\mathrm{mmHg}$ ). The atria and the right ventricle were removed, and the left ventricle (LV), including the septum, was cut into 2- to 3-mm slices from the apex to the base. The perfused myocardium was stained blue, whereas the AAR remained unstained. The AAR was determined as the percentage of the ischemic myocardial mass against the LV myocardial mass. The unstained myocardium was incubated for $30 \mathrm{~min}$ at $37^{\circ} \mathrm{C}$ in TTC (1\% in $0.1 \mathrm{~mol} / 1$ phosphate buffer, $\left.\mathrm{pH} 7.4\right)$. The noninfarcted myocardium was deep red, in contrast to the pale white of the infarcted myocardium. The IS was expressed as the percentage of the infarcted myocardial mass against the ischemic myocardial mass.

Biochemical parameters. The serum obtained from the rats was used for the measurement of MB-isoenzyme of creatine kinase (CK-MB), TNF $\alpha$, IL-1 $\beta$, IL- 6 and ICAM-1 levels. CK-MB level was determined following the homogenization of the rat myocardium in lysis buffer from BioTeke Corporation (Beijing, China). TNF $\alpha$, IL-1 $\beta$, IL-6, ICAM-1 aand MDA levels, and SOD activity were determined following the homogenization of the rat myocardium in lysis buffer from Nanjing Jiancheng 
Table III. Effect of FPCG on increasing superoxide dismutase activity in the rat myocardium following ischemia-reperfusion.

\begin{tabular}{lcccc}
\hline Source of variation & Mean-square & $F$ & P-value & $\mathrm{n}$ \\
\hline Ferulic acid & 130.805 & 1.958 & 0.155 & 6 \\
Peoniflorin & 22.190 & 0.332 & 0.802 & 6 \\
Cinnamic acid & 15.898 & 0.238 & 0.869 & 6 \\
Glycyrrhizic acid & 322.778 & 4.833 & 0.012 & 6 \\
\hline
\end{tabular}

Results were assessed by analysis of variance. FPCG, ferulic acid, peoniflorin, cinnamic acid and glycyrrhizic acid combination.

Technology Co., Ltd. In addition, the protein content of all tissues was determined using the BCA method.

Electron microscopy. For the ultrastructural morphological study, the samples were fixed with $2.5 \%$ glutaraldehyde solution, and then dehydrated in a graded series of ethanol, $1 \%$ $\mathrm{O}_{5} \mathrm{O}_{4}$, phosphate-buffered saline and acetone, and embedded in Epon812 embedding medium. The ultrathin sections were prepared on a Reichert-Jung Ultracut E ultramicrotome (Leica Corporation, Shanghai, China), picked up on copper grids and stained. Specimens were observed under a JEM-100CX electron microscope (JEOL Japan Electronics Co., Ltd. Tokyo, Japan).

Histological examination. Myocardial tissues of SD rats were fixed in $10 \%$ neutral formaldehyde for $24 \mathrm{~h}$, and then each sample was dehydrated with segments embedded in paraffin and cut into $5-\mu \mathrm{m}$ thick sections for staining with hematoxylin and eosin (H\&E).

Western blot analysis. Rat myocardium was homogenized in lysis buffer $(50 \mathrm{~mm}$ Tris $\mathrm{pH} \mathrm{7.4,150} \mathrm{mm} \mathrm{NaCl,} 1 \%$ Triton $\mathrm{X}-100,1 \%$ sodium deoxycholate, $0.1 \%$ SDS, EDTA and protease inhibitor cocktail) and centrifuged at 3,000 x g for 10 min. Protein concentration was determined using a BCA protein assay kit according to the manufacturer's instructions (Nanjing KeyGen Biotech. Co., Ltd.). Equal amounts of protein (100 $\mu \mathrm{g} / \mathrm{sample})$ were electrophoresed by SDS-PAGE and transferred onto a polyvinylidene difluoride membrane. The membrane was blocked with $5 \%$ non-fat milk in $1 \mathrm{X}$ Tris buffered saline and $0.1 \%$ Tween 20 at room temperature for $3 \mathrm{~h}$. The membrane was then incubated overnight at $4^{\circ} \mathrm{C}$ with the appropriate primary antibody [anti-phospho-I- $\kappa \mathrm{B} \alpha(\mathrm{Ser} 32 / 36)$, anti-I- $\kappa \mathrm{B} \alpha$, anti-NF- $\kappa \mathrm{Bp} 65$, anti-PPAR $\alpha$, anti-GAPDH or anti-phospho-Akt1/2] diluted in Tris buffered saline/Tween 20 (Tris buffered saline, $0.1 \%$ Tween 20 ). The working concentrations of the anti-phospho-I- $\kappa \mathrm{B} \alpha$ (Ser32/36), anti-I- $\kappa \mathrm{B} \alpha$, anti-NF- $\kappa$ Bp65, anti-PPAR $\alpha$, anti-pAkt1/2 and anti-GAPDH antibodies were 1:500, 1:1,000, 1:1,000, 1:1,000, 1:500 and $1: 2,000$, respectively. Following incubation with peroxidase-conjugated goat anti-rabbit IgG secondary antibodies for $1 \mathrm{~h}$, the blots were developed with chemiluminescence reagent and exposed to X-ray film. Nuclear protein was then extracted using an extraction kit according to the manufacturer's instructions (Nanjing KeyGen Biotech. Co., Ltd.). Band intensities were quantified using a densitometer analysis system (Quantity One ${ }^{\circledR}$, Bio-Rad, Hercules, CA, USA).
Statistical analysis. Data are presented as the mean \pm standard deviation. Statistical analysis for the experimental groups was performed using SPSS for Windows version 13.0 (SPSS, Inc., Chicago, IL, USA). Differences among groups were compared with one-way analysis of variance (ANOVA) followed by the Dunnett's test. Differences were considered statistically significant when $\mathrm{P}<0.05$. The variance analysis was applied in the orthogonal experiment.

\section{Results}

Detection of serum components by HPLC following oral administration of DGSN. The results (Fig. 1A-D) showed the DGSN decoction contained FPCG detected in serum of rats following oral administration of the DGSN decoction by HPLC analysis.

Orthogonal-design experiment results. In the orthogonal experiments (Tables III-VI), SOD activity was assessed using the xanthine oxidase method and MDA levels were measured using the thiobarbituric acid-reactive-substances assay. Through ANOVA and the orthogonal experiment intuitionistic approach, it was found that glycyrrhizic acid was the most effective component at increasing SOD activity in the rat myocardium following I/R; ferulic acid, peoniflorin and cinnamic acid were second-most, third-most and least effective, respectively. The optimal drug combination was glycyrrhizic acid $(50 \mathrm{mg} / \mathrm{kg})$, cinnamic acid $(0 \mathrm{mg} / \mathrm{kg})$, ferulic acid $(0 \mathrm{mg} / \mathrm{kg})$ and peoniflorin $(0 \mathrm{mg} / \mathrm{kg})$. In addition, it was found that cinnamic acid was the most effective component at reducing MDA levels in the rat myocardium following I/R; ferulic acid, peoniflorin and glycyrrhizic acid were second-most, third-most and least effective, respectively. The optimal drug combination was cinnamic acid $(200 \mathrm{mg} / \mathrm{kg})$, ferulic acid $(300 \mathrm{mg} / \mathrm{kg})$, peoniflorin $(0 \mathrm{mg} / \mathrm{kg})$ and glycyrrhizic acid $(0 \mathrm{mg} / \mathrm{kg})$. Taking both sets of results into consideration, the combination of glycyrrhizic acid $(50 \mathrm{mg} / \mathrm{kg})$, cinnamic acid (200 mg/kg) and ferulic acid (300 mg/kg) (FCG) was regarded as optimal. This not only lowered the content of MDA, but also increased the activity of SOD.

Effect of FCG pretreatment on biochemical parameters induced by I/R injury. TNF $\alpha$, IL-1 $\beta$, IL-6 and ICAM-1 levels were detected by ELISA assay, and the presence of CK-MB was revealed by enzyme rate assay. As shown in Tables VII and VIII, the levels of TNF $\alpha$, IL-1 $\beta$, IL-6, ICAM-1 and CK-MB were 
Table IV. Effect of FPCG on increasing SOD activity in the rat myocardium following ischemia-reperfusion.

\begin{tabular}{|c|c|c|c|c|c|}
\hline Group & Glycyrrhizic acid (A) & Ferulic acid (B) & Peoniflorin (C) & Cinnamic acid (D) & $\mathrm{SOD}(\mathrm{U} / \mathrm{mg})$ \\
\hline 1 & 1 & 1 & 1 & 1 & $25.63 \pm 7.73$ \\
\hline 2 & 3 & 3 & 1 & 3 & $50.01 \pm 1.97$ \\
\hline 3 & 4 & 4 & 1 & 4 & $48.21 \pm 7.83$ \\
\hline 4 & 2 & 2 & 1 & 2 & $35.54 \pm 4.73$ \\
\hline 5 & 2 & 4 & 3 & 1 & $38.85 \pm 0.79$ \\
\hline 6 & 4 & 3 & 2 & 1 & $46.89 \pm 1.05$ \\
\hline 7 & 3 & 2 & 4 & 1 & $49.96 \pm 7.48$ \\
\hline 8 & 1 & 4 & 4 & 3 & $36.23 \pm 0.66$ \\
\hline 9 & 4 & 1 & 4 & 2 & $45.12 \pm 8.51$ \\
\hline 10 & 1 & 3 & 3 & 2 & $43.30 \pm 4.49$ \\
\hline 11 & 2 & 3 & 4 & 4 & $40.71 \pm 4.04$ \\
\hline 12 & 2 & 1 & 2 & 3 & $31.86 \pm 0.97$ \\
\hline 13 & 3 & 1 & 3 & 4 & $41.26 \pm 4.59$ \\
\hline 14 & 3 & 4 & 2 & 2 & $47.21 \pm 6.67$ \\
\hline 15 & 4 & 2 & 3 & 3 & $40.21 \pm 6.05$ \\
\hline 16 & 1 & 2 & 2 & 4 & $30.85 \pm 5.92$ \\
\hline $\mathrm{K}_{1}$ & 34.00 & 35.96 & 39.85 & 40.33 & - \\
\hline $\mathrm{K}_{2}$ & 36.74 & 39.14 & 39.20 & 42.79 & - \\
\hline $\mathrm{K}_{3}$ & 47.11 & 45.23 & 40.90 & 39.58 & - \\
\hline $\mathrm{K}_{4}$ & 45.11 & 42.62 & 43.00 & 40.25 & - \\
\hline$R_{j}$ & 13.10 & 9.26 & 3.80 & 2.54 & - \\
\hline
\end{tabular}

1,2,3 and 4 represent no drug, low dose, medium dose and high dose, respectively. Data were analyzed using the orthogonal experiment intuitionistic analytical approach and are presented as the mean \pm standard deviation. SOD, superoxide dismutase; FPCG, ferulic acid, peoniflorin, cinnamic acid and glycyrrhizic acid combination; $\mathrm{K}_{\mathrm{x}}$, mean of a certain factor $\mathrm{K}$ at a particular level $\mathrm{x} ; \mathrm{R}_{\mathrm{j}}$, range of the column (denoted as $\mathrm{J}$ ) of a certain factor.

Table V. Effect of FPCG on reducing malondialdehyde levels in the rat myocardium following ischemia-reperfusion.

\begin{tabular}{lccc}
\hline Source of variation & Mean-square & $F$ & P-value \\
\hline Ferulic acid & 0.167 & 3.32 & 0.032 \\
Peoniflorin & 0.119 & 2.367 & 0.090 \\
Cinnamic acid & 0.231 & 4.582 & 0.009 \\
Glycyrrhizic acid & 0.067 & 1.337 & 0.280 \\
\hline
\end{tabular}

Results were assessed by analysis of variance. FPCG, ferulic acid, peoniflorin, cinnamic acid and glycyrrhizic acid combination.

increased significantly in the myocardium of rats with I/R injury as compared with those in the myocardium of sham-operated rats. However, administering FCG pretreatment for five days before the I/R injury significantly decreased the serum levels of TNF $\alpha$, IL-1 $\beta$, IL-6, ICAM-1 and CK-MB as compared with the levels in the I/R group without pretreatment.

Effect of FCG pretreatment on myocardial IS and AAR. The AAR and IS are a percentage of the LV and AAR weights, respectively. AAR and IS were used to assess the efficacy of the FCG combination in the protection of the rat myocardium following I/R injury. Significant differences were not apparent among the three groups with regard to the AAR. The values for the IS were $0.17 \pm 0.01 \%$ in the FCG pretreatment group and $0.29 \pm 0.08 \%$ in the I/R group. Significant differences in IS were observed between the FCG pretreatment group (PPC plus I/R) and the I/R group (Fig. 2A-C).

Effect of FCG pretreatment on histological changes induced by I/R injury. The histomorphology of the cardiac muscle of the $\mathrm{LV}$ of the rats was observed using H\&E staining. The following changes were found in the I/R group: Muscle fiber disarrangement, clear hydropic degeneration, cell dropsy, dark nuclear staining, vascular bleeding, inflammatory cell infiltration and 
Table VI. Effect of FPCG on reducing MDA levels in the rat myocardium following ischemia-reperfusion.

\begin{tabular}{|c|c|c|c|c|c|}
\hline Group & Glycyrrhizic acid & Ferulic acid & Peoniflorin & Cinnamic acid & $\mathrm{MDA}(\mathrm{nmol} / \mathrm{mg})$ \\
\hline 1 & 1 & 1 & 1 & 1 & $0.99 \pm 0.11$ \\
\hline 2 & 3 & 3 & 1 & 3 & $0.43 \pm 0.07$ \\
\hline 3 & 4 & 4 & 1 & 4 & $0.48 \pm 0.31$ \\
\hline 4 & 2 & 2 & 1 & 2 & $0.43 \pm 0.12$ \\
\hline 5 & 2 & 4 & 3 & 1 & $1.19 \pm 0.03$ \\
\hline 6 & 4 & 3 & 2 & 1 & $0.66 \pm 0.11$ \\
\hline 7 & 3 & 2 & 4 & 1 & $0.65 \pm 0.20$ \\
\hline 8 & 1 & 4 & 4 & 3 & $0.58 \pm 0.32$ \\
\hline 9 & 4 & 1 & 4 & 2 & $0.54 \pm 0.05$ \\
\hline 10 & 1 & 3 & 3 & 2 & $0.45 \pm 0.12$ \\
\hline 11 & 2 & 3 & 4 & 4 & $0.40 \pm 0.07$ \\
\hline 12 & 2 & 1 & 2 & 3 & $0.58 \pm 0.12$ \\
\hline 13 & 3 & 1 & 3 & 4 & $0.73 \pm 0.14$ \\
\hline 14 & 3 & 4 & 2 & 2 & $0.89 \pm 0.23$ \\
\hline 15 & 4 & 2 & 3 & 3 & $0.48 \pm 0.12$ \\
\hline 16 & 1 & 2 & 2 & 4 & $0.86 \pm 0.30$ \\
\hline $\mathrm{K}_{1}$ & 0.72 & 0.71 & 0.58 & 0.62 & - \\
\hline $\mathrm{K}_{2}$ & 0.65 & 0.61 & 0.75 & 0.58 & - \\
\hline $\mathrm{K}_{3}$ & 0.67 & 0.48 & 0.71 & 0.52 & - \\
\hline $\mathrm{K}_{4}$ & 0.54 & 0.78 & 0.54 & 0.87 & - \\
\hline $\mathrm{R}_{\mathrm{j}}$ & 0.18 & 0.30 & 0.21 & 0.36 & - \\
\hline
\end{tabular}

1, 2, 3 and 4 represent no drug, low dose, medium dose and high dose, respectively. Data were analyzed using the orthogonal experiment intuitionistic analytical approach and are presented as the mean \pm standard deviation. MDA, malondialdehyde; FPCG, ferulic acid, peoniflorin, cinnamic acid and glycyrrhizic acid combination.

Table VII. Effects of FCG pretreatment on serum TNFa and ICAM-1 levels in the rat myocardium following ischemia-reperfusion.

\begin{tabular}{llc}
\hline Group & TNF $\alpha(\mathrm{ng} / \mathrm{l})$ & ICAM-1 (ng/l) \\
\hline Sham & $21.85 \pm 3.96^{\mathrm{a}}$ & $19.90 \pm 1.02^{\mathrm{a}}$ \\
I/R & $46.77 \pm 6.54$ & $35.20 \pm 3.34$ \\
PPC+I/R & $33.54 \pm 4.95^{\mathrm{a}}$ & $23.07 \pm 1.73^{\mathrm{a}}$ \\
\hline
\end{tabular}

Data are presented as the mean \pm standard deviation; $\mathrm{n}=6 .{ }^{\mathrm{a}} \mathrm{P}<0.05$ vs. I/R. Sham, sham-operated animal without ligation; I/R, $30 \mathrm{~min}$ ischemia followed by $2 \mathrm{~h}$ reperfusion; PPC+I/R, administration of FCG for 5 days prior to the induction of myocardial ischemia. FCG, ferulic acid $(300 \mathrm{mg} / \mathrm{kg})$, cinnamic acid $(200 \mathrm{mg} / \mathrm{kg})$ and glycyrrhizic acid $(50 \mathrm{mg} / \mathrm{kg}) ; \mathrm{TNF} \alpha$, tumor necrosis factor- $\alpha$; ICAM-1, intercellular adhesion molecule-1.

myocardial fiber atrophy. These morphological changes were alleviated by FCG pretreatment (Fig. 3).

Effect of FCG pretreatment on ultrastructural changes induced by I/R injury. The ultrastructural changes in the cardiac muscle of the LV of the rats were observed by transmission electron
Table VIII. Effects of FCG pretreatment on serum IL-1 $\beta$, IL-6 and CK-MB levels in the rat myocardium following ischemia-reperfusion.

\begin{tabular}{lllr}
\hline Group & IL-1 $\beta(n g / l)$ & IL-6 (ng/l) & CK-MB (U/l) \\
\hline Sham & $18.29 \pm 5.32^{\mathrm{a}}$ & $12.11 \pm 2.11^{\mathrm{a}}$ & $229.45 \pm 21.08$ \\
I/R & $26.44 \pm 8.24$ & $34.32 \pm 6.50$ & $1025.50 \pm 88.19$ \\
PPC+I/R & $19.20 \pm 2.47^{\mathrm{a}}$ & $16.77 \pm 4.22^{\mathrm{a}}$ & $427.54 \pm 59.18$
\end{tabular}

Data are presented as the mean \pm standard deviation; $n=6$. ${ }^{\mathrm{a}} \mathrm{P}<0.05$ vs. I/R. Sham, sham-operated animal without ligation; I/R, $30 \mathrm{~min}$ ischemia followed by $2 \mathrm{~h}$ reperfusion; PPC+I/R, administration of FCG for 5 days prior to the induction of myocardial ischemia. FCG, ferulic acid $(300 \mathrm{mg} / \mathrm{kg})$, cinnamic acid $(200 \mathrm{mg} / \mathrm{kg})$ and glycyrrhizic acid $(50 \mathrm{mg} / \mathrm{kg}) ; \mathrm{IL}$, interleukin; CK-MB, MB-isoenzyme of creatine kinase.

microscopy (Fig. 4). These changes included cell swelling, mitochondrial swelling, cristae disorganization, myofibril shrinkage and lysis, chromatin condensation and aggregation at the periphery of the nucleus and nuclear fragmentation. Apoptotic bodies were also observed in the I/R group. The aforementioned ultrastructural changes were alleviated in the PPC plus I/R group as compared with the $\mathrm{I} / \mathrm{R}$ group. 
A

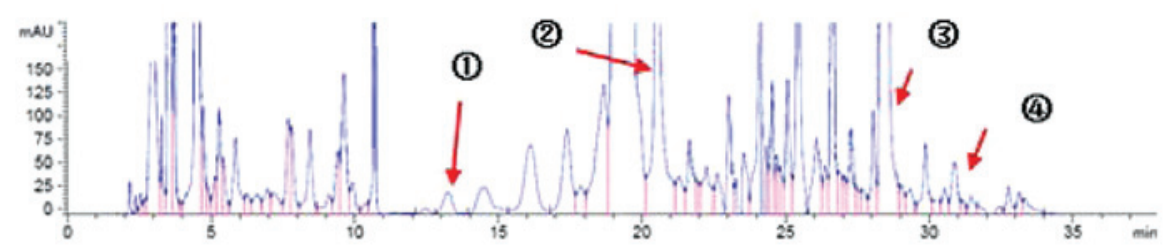

B

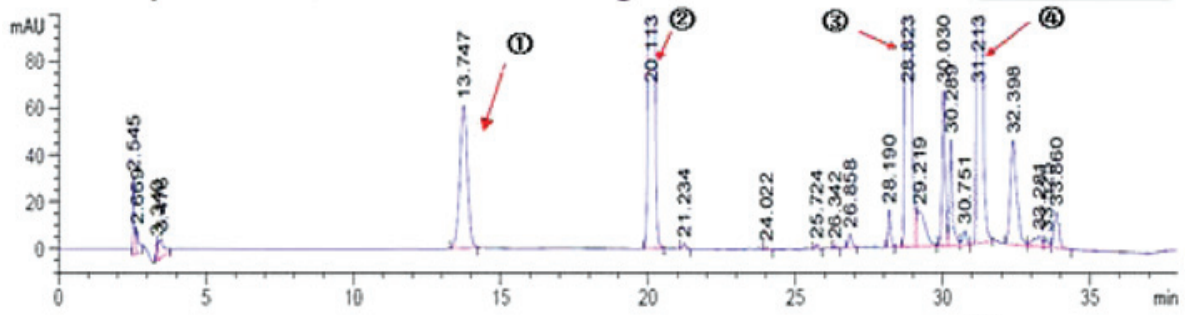

C

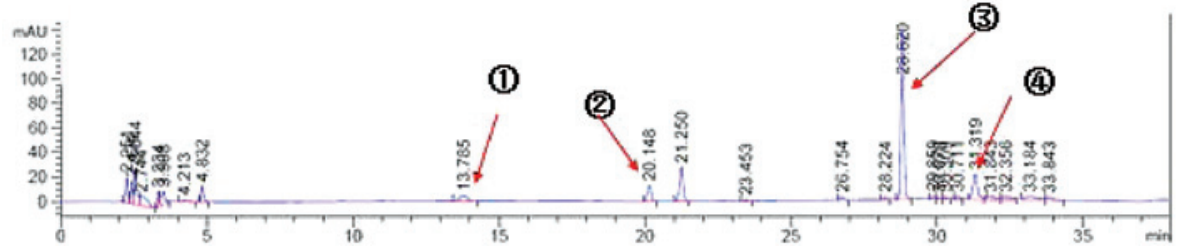

D

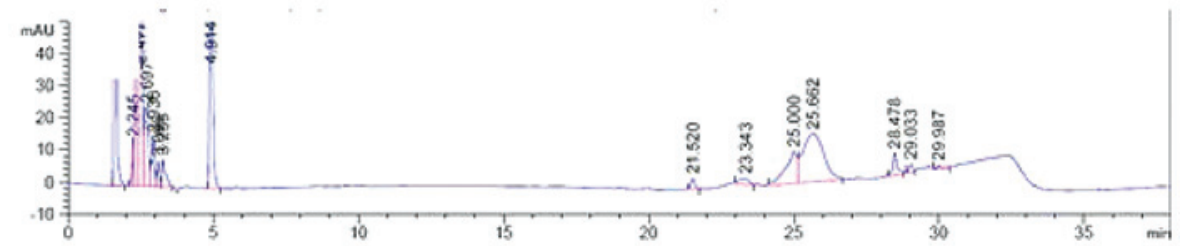

Figure 1. High-performance liquid chromatography chromatograms of (A) Dang-gui-ni-tang decoction extracted by n-butanol; (B) the standard sample; (C) the serum sample; and (D) the blank serum. The peaks marked as (1), (2), (3) and (4) are peoniflorin and ferulic, cinnamic and glycyrrhizic acids, respectively. The detection wavelength was $275 \mathrm{~nm}$.

A

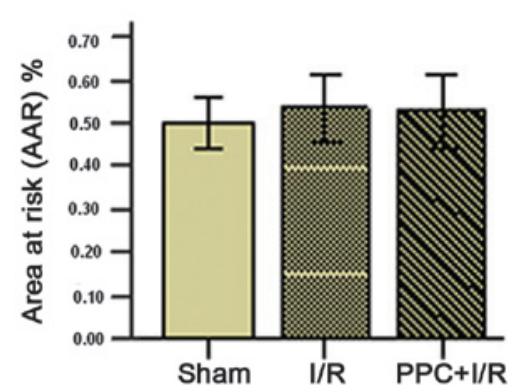

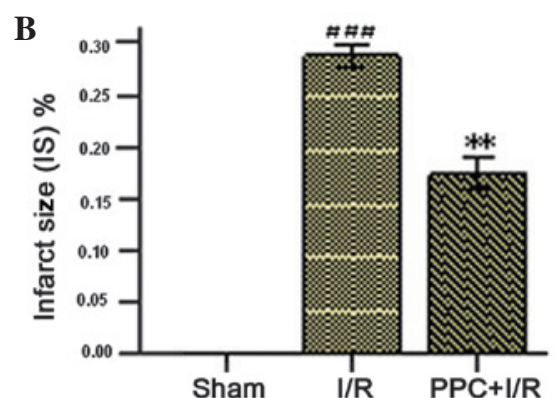
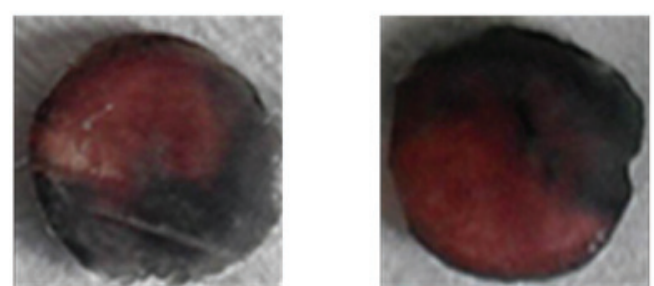

Figure 2. Effects of FCG on (A) myocardial AAR and (B) IS. (C) Images of the myocardial AAR and infarct area in the sham, I/R and PPC+I/R groups (left, center and right, respectively). The area of infarct is white, the myocardial AAR is deep red and the nonischemic area is blue. Data are presented as the mean \pm standard deviation; $\mathrm{n}=6 .{ }^{* * *} \mathrm{P}<0.01$ vs. I/R; ${ }^{\# \# *} \mathrm{P}<0.001$ vs. sham, $\mathrm{n}=6$. Sham, sham-operated animal without ligation; $\mathrm{I} / \mathrm{R}, 30 \mathrm{~min}$ ischemia followed by $2 \mathrm{~h}$ reperfusion; $\mathrm{PPC}+\mathrm{I} / \mathrm{R}$, administration of FCG for 5 days prior to the induction of myocardial ischemia. FCG, ferulic acid $(300 \mathrm{mg} / \mathrm{kg}), \mathrm{cinnamic}$ acid $(200 \mathrm{mg} / \mathrm{kg})$ and glycyrrhizic acid $(50 \mathrm{mg} / \mathrm{kg}) ; \mathrm{AAR}$, area at risk; IS, infarct size.

Effect of FCG pretreatment on the expression of $I-\kappa B \alpha$, $N F-\kappa B, p 65, P P A R \alpha$ and $p A k t 1 / 2$ induced by I/R injury. The effects of pharmacological pretreatment with FCG on nuclear

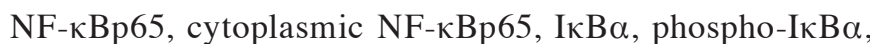
PPAR $\alpha$ and phospho-Akt proteins in the myocardium of rats were detected by western blot analysis (Figs. 5-8). Compared 


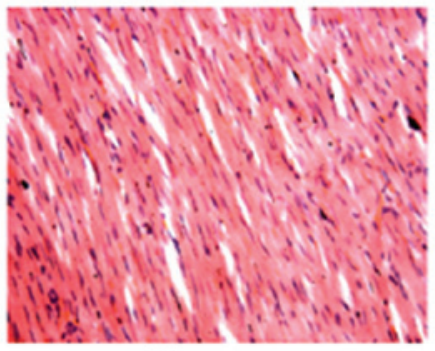

Sham

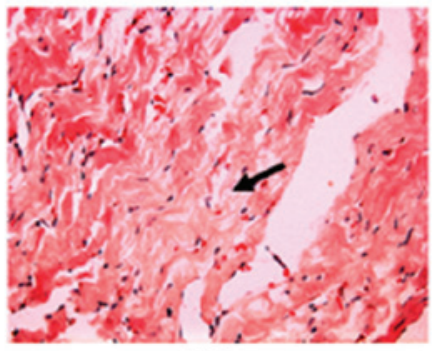

I/R

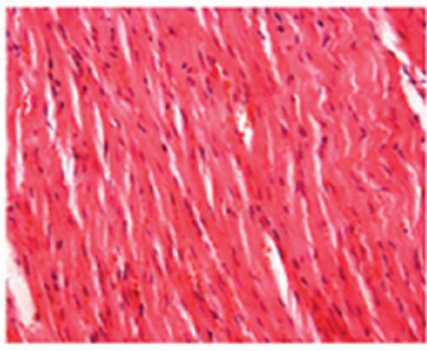

$\mathrm{PPC}+\mathrm{I} / \mathrm{R}$

Figure 3. Morphology of rat myocardium (hematoxylin and eosin staining; magnification, $\mathrm{x} 200$ ). Sham, sham-operated animal without ligation; I/R, 30 min ischemia followed by $2 \mathrm{~h}$ reperfusion; PPC+I/R, administration of FCG for 5 days prior to the induction of myocardial ischemia. The arrow indicates muscle fiber disarranging and clear hydropic degeneration. FCG, ferulic acid (300 mg/kg), cinnamic acid $(200 \mathrm{mg} / \mathrm{kg})$ and glycyrrhizic acid $(50 \mathrm{mg} / \mathrm{kg})$.

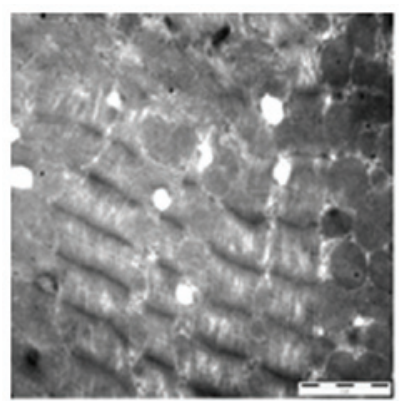

Sham

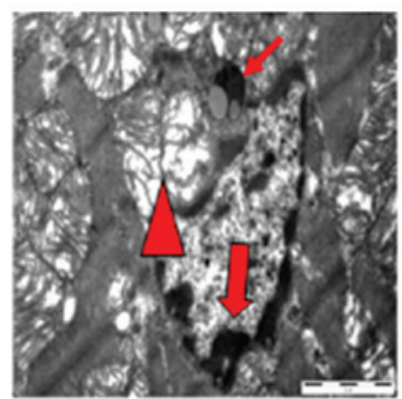

I/R

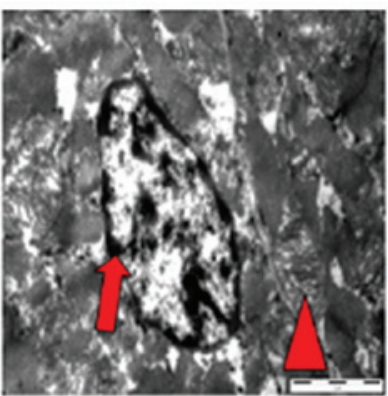

$\mathrm{PPC}+\mathrm{I} / \mathrm{R}$

Figure 4. Electron microscopic examination of rat myocardium (magnification, $\mathrm{x} 15,000$ ). Sham, sham-operated animal without ligation; I/R, $30 \mathrm{~min}$ ischemia followed by $2 \mathrm{~h}$ reperfusion; PPC+I/R, administration of FCG for 5 days prior to the induction of myocardial ischemia. Thin arrows indicate apoptotic bodies, $\Delta$ indicates swelling mitochondria, large arrows indicate chromatin condensation and aggregation. FCG, ferulic acid $(300 \mathrm{mg} / \mathrm{kg}), \mathrm{cinnamic} \mathrm{acid}(200 \mathrm{mg} / \mathrm{kg})$ and glycyrrhizic acid $(50 \mathrm{mg} / \mathrm{kg})$.
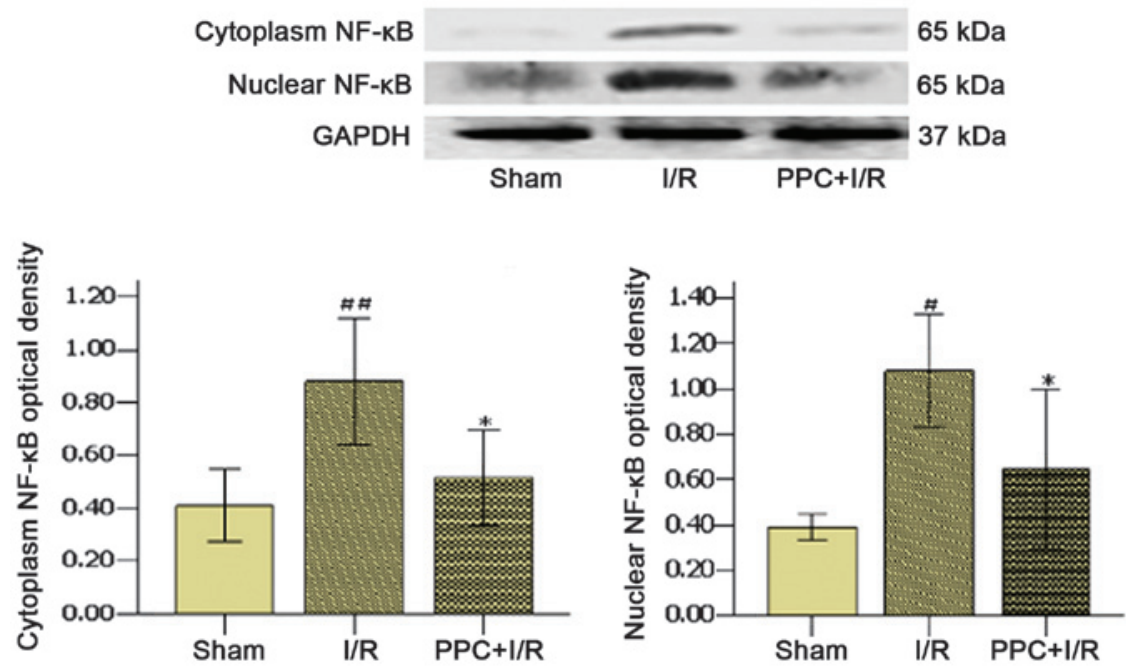

Figure 5. Effect of FCG pretreatment on cytoplasmic and nuclear NF- $\mathrm{kBp} 65$ expression in different groups. Data are presented as the mean \pm standard deviation; $\mathrm{n}=6$. " $\mathrm{P}<0.05$ vs. I/R; ${ }^{\# \#} \mathrm{P}<0.001$ and ${ }^{\#} \mathrm{P}<0.05$ vs. sham. Sham, sham-operated animal without ligation; I/R, 30 min ischemia followed by $2 \mathrm{~h}$ reperfusion; PPC+I/R, administration of FCG for 5 days prior to the induction of myocardial ischemia. FCG, ferulic acid (300 mg/kg), cinnamic acid (200 mg/kg) and

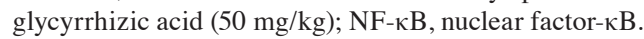

with the sham group, the expression levels of NF-kBp65 and phospho-I- $\kappa \mathrm{B}$ were significantly increased in the I/R group,

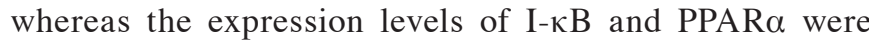
decreased. The levels of phospho-Akt were increased in the $\mathrm{I} / \mathrm{R}$ group, although the difference was not significant. However, compared with the I/R group, the expression of NF- $\mathrm{KBp} 65$ and phospho-I- $\kappa \mathrm{B}$ was significantly decreased, whereas the expres- sion of I- $\kappa \mathrm{B}, \mathrm{PPAR} \alpha$ and phospho-Akt was increased in the PPC plus I/R group.

\section{Discussion}

The results of the present study showed that, while a number of chemical constituents were contained in DGSN decoction, 

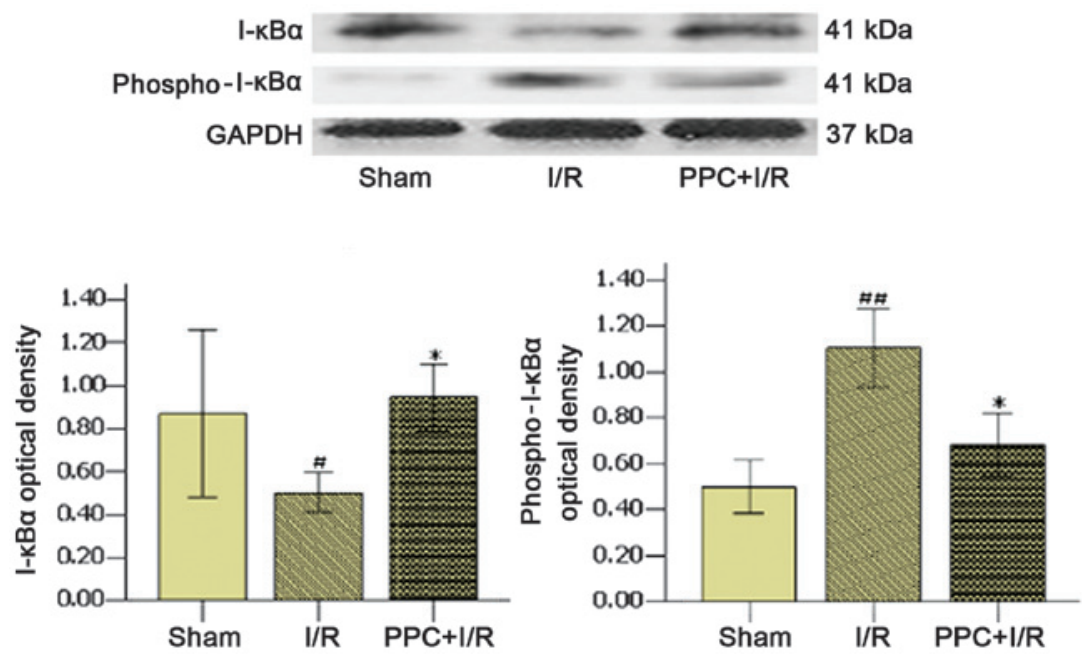

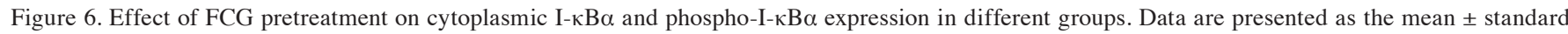
deviation; $\mathrm{n}=6$. ${ }^{*} \mathrm{P}<0.05$ vs. I/R; ${ }^{\# \#} \mathrm{P}<0.001$ and ${ }^{\#} \mathrm{P}<0.05$ vs. sham. Sham, sham-operated animal without ligation; $\mathrm{I} / \mathrm{R}, 30 \mathrm{~min}$ ischemia followed by $2 \mathrm{~h}$ reperfusion; PPC+I/R, administration of FCG for 5 days prior to the induction of myocardial ischemia. FCG, ferulic acid ( $300 \mathrm{mg} / \mathrm{kg})$, cinnamic acid (200 mg/kg) and

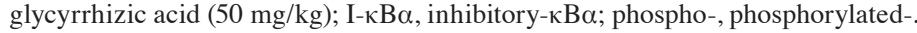
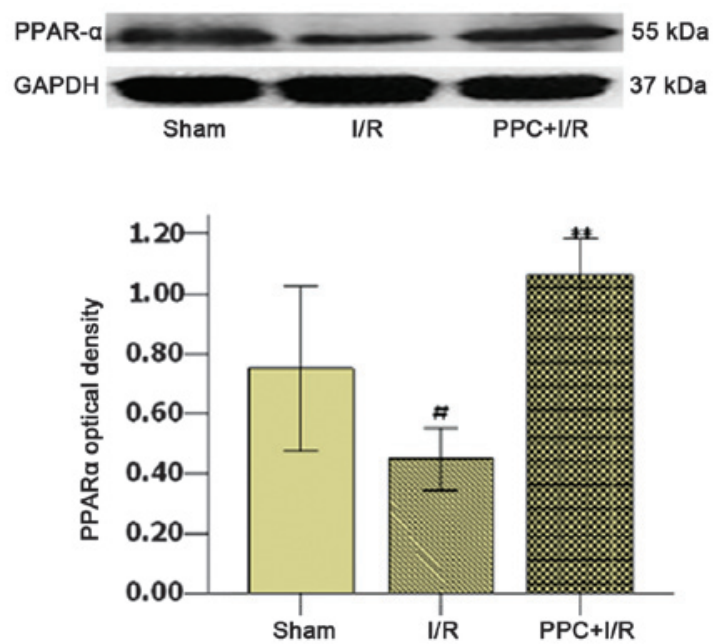

Figure 7. Effect of FCG pretreatment on PPAR $\alpha$ protein expression in different groups. Data are presented as the mean \pm standard deviation; $\mathrm{n}=6$. ${ }^{* * *} \mathrm{P}<0.05$ vs. I/R; ${ }^{*} \mathrm{P}<0.05$ vs. sham. Sham, sham-operated animal without ligation; I/R, $30 \mathrm{~min}$ ischemia followed by $2 \mathrm{~h}$ reperfusion; $\mathrm{PPC}+\mathrm{I} / \mathrm{R}$, administration of FCG for 5 days prior to the induction of myocardial ischemia. FCG, ferulic acid $(300 \mathrm{mg} / \mathrm{kg})$, cinnamic acid $(200 \mathrm{mg} / \mathrm{kg})$ and glycyrrhizic acid $(50 \mathrm{mg} / \mathrm{kg}) ;$ PPAR $\alpha$, peroxisome proliferator-activated receptor $\alpha$.

a Traditional Chinese Medicine (Fig. 1A), $<10$ types of constituent could be absorbed into the blood (Fig. 1C) following oral administration of the DGSN decoction. Only the components that can be absorbed into the blood may play a role in pharmacology. Therefore, the objective of our study was to investigate which components could be absorbed following oral administration of DGSN decoction, and to then find the optimal drug cocktail composition from the absorbable components, in order to treat $\mathrm{I} / \mathrm{R}$ injury of the rat myocardium through orthogonal experiments. The mechanism of the optimal cocktail composition was then further explored.

DGSN effectively treats coronary heart diseases. Cinnamic, glycyrrhizic and ferulic acids, and peoniflorin can be detected in DGSN decoction (9-11), and in the serum of rats following the
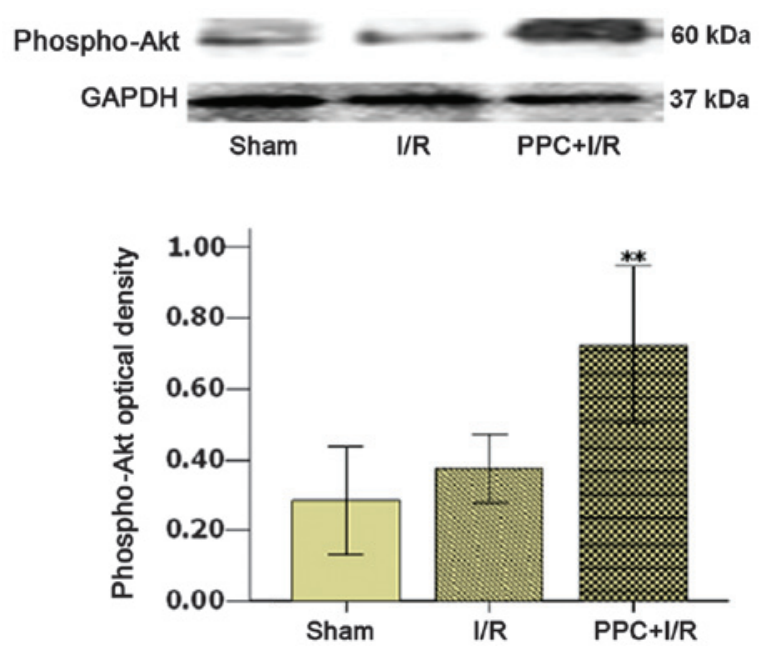

Figure 8. Effect of FCG pretreatment on phospho-Akt protein expression in different groups. Data are presented as the mean \pm standard deviation; $n=6$. ${ }^{* *} \mathrm{P}<0.05$ vs. I/R. Sham, sham-operated animal without ligation; I/R, $30 \mathrm{~min}$ ischemia followed by $2 \mathrm{~h}$ reperfusion; $\mathrm{PPC}+\mathrm{I} / \mathrm{R}$, administration of $\mathrm{FCG}$ for 5 days prior to the induction of myocardial ischemia. FCG, ferulic acid (300 mg/kg), cinnamic acid (200 mg/kg) and glycyrrhizic acid $(50 \mathrm{mg} / \mathrm{kg})$; phospho-, phosphorylated-.

oral administration of DGSN decoction (Fig. 1A-D). A number of studies have reported that glycyrrhizic $(28)$, ferulic $(29,30)$ and cinnamic $(31,32)$ acids can alleviate damage following $\mathrm{I} / \mathrm{R}$ injury, respectively. Therefore, it may be hypothesized that the optimal drug combination for treating rat myocardial I/R injury may be derived from the components of DGSN.

In multifactor experiments, an orthogonal experiment design enables the hierarchical status of the factors and the interaction among the factors to be established, which facilitates the determination of the ideal combination of multiple factors with as few sampling experiments as possible. In pharmacodynamic studies of multiple factors, the optimal drug combinations can be revealed by orthogonal experiment design. The $L 16\left(4^{4}\right)$ orthogonal design was selected in the present study to find 
an optimal cocktail drug combination from the components absorbed following the oral administration of DGSN decoction. The strength of effect as well as correlations among components in the cocktail drug combinations were detected. SOD activity and MDA levels represent an evaluation index to measure the effectiveness among these components and cocktail drug combinations, since these indexes can respond to the damage degrees of oxidative stress and inflammation. Reperfusion is essential for myocardial tissue survival. However, its effect on ischemic myocardium is two-fold, as it can trigger oxidative tissue damage and inflammation $(23,27,33,34)$. Furthermore, the inflammatory response and oxidative damage are important causes of myocardial I/R injury (35). The MDA content can respond to the degree of lipid peroxidation, and the modulation of antioxidant enzymes, such as SOD and catalase, can protect against oxidative cardiac disorders $(36,37)$.

In the present study, the $L 16\left(4^{4}\right)$ orthogonal experiment intuitionistic analytical approach was used to find the most effective component at reducing MDA levels in the rat myocardium following I/R. The most effective component was cinnamic acid, followed by ferulic acid, peoniflorin and glycyrrhizic acid. However, ANOVA showed that only cinnamic acid and ferulic acid were capable of significantly decreasing the content of MDA (Table V). In addition, it was found that the most effective component at increasing SOD activity in the rat myocardium following I/R was glycyrrhizic acid, followed by ferulic acid, peoniflorin and cinnamic acid. However, ANOVA showed that only glycyrrhizic acid significantly increased the activity of SOD (Table III). Summarizing the results of the SOD activity and MDA level analysis, FCG was revealed to be the optimal drug combination, consisting of glycyrrhizic $(50 \mathrm{mg} / \mathrm{kg})$, cinnamic $(200 \mathrm{mg} / \mathrm{kg})$ and ferulic $(300 \mathrm{mg} / \mathrm{kg})$ acid. This combination not only reduced the content of MDA, but also increased the activity of SOD.

In the present study the second step was to explore the mechanism underlying the effect of FCG on I/R injury. The effects could be observed in a number of aspects, including myocardial IS, myocardial tissue construction, cell ultrastructure, inflammatory and biochemical parameters, signaling pathways of the inflammatory response and oxidative damage. The results showed that FCG could decrease myocardial IS (Fig. 2). The following changes were also revealed: Muscle fiber disarrangement, clear hydropic degeneration, cell dropsy, dark nuclear staining, vascular bleeding and inflammatory cell infiltration. These changes were significantly alleviated by FCG pretreatment compared with the I/R group. In addition, the cardiac muscle ultrastructural changes were observed via transmission electron microscopy (Fig. 4). These included cell swelling, mitochondrial swelling, cristae disorganization, myofibril shrinkage and lysis. Chromatin condensation and aggregation at the periphery of the nucleus and nuclear fragmentation were shown to be significantly alleviated by FCG pretreatment compared with the I/R group.

$\mathrm{NF}-\kappa \mathrm{B}$ is an important transcriptional regulatory factor and plays an important role in myocardial I/R injury. Furthermore, $\mathrm{NF}-\kappa \mathrm{B}$ has a close association with the inflammatory response and oxidative damage. I/ $\mathrm{R}$ injury can cause a rapid phosphorylation of $\mathrm{I}-\kappa \mathrm{B} \alpha$ and degradation of $\mathrm{I}-\kappa \mathrm{B} \alpha(\mathrm{I}-\kappa \mathrm{B} \alpha$ is the inhibitory protein of $N F-\kappa B$ activation). This leads to the activation of $\mathrm{NF}-\kappa \mathrm{B}$ translocation into the nucleus and the transcription of other downstream inflammatory factors, including TNF $\alpha$,
IL-1 $\beta$, IL-6 and ICAM-1 (38-40). PPAR $\alpha$ is an important regulatory factor of $\mathrm{NF}-\kappa \mathrm{B}(41,42)$ that, following activation by its ligands, can suppress the activation and nuclear translocation of $\mathrm{NF}-\kappa \mathrm{B}$ (43), repress the expression of inflammatory factors and increase the expression of SOD $(41,44-46)$. PPAR $\alpha$ is closely associated with the Akt signal transduction pathway (47). In the present study, the expression levels of TNF $\alpha$, IL-1 $\beta$, IL-6, ICAM-1, NF- $\kappa$ Bp65 and phospho-I- $\kappa \mathrm{B} \alpha$ were detected to be significantly increased in the I/R group, while the expression levels of I- $\kappa \mathrm{B} \alpha$, PPAR $\alpha$ were significantly decreased. The levels of phospho-Akt were increased in the I/R group compared with the sham group, although the difference was not significant. However, compared with the I/R group, the expression levels of TNF $\alpha$, IL-1 $\beta$, IL-6 and ICAM-1 significantly decreased with FCG pretreatment. Furthermore, the expression levels of $\mathrm{NF}-\kappa \mathrm{Bp} 65$ and phospho-I- $\kappa \mathrm{B} \alpha$ significantly decreased, and the expression of I- $\kappa \mathrm{B} \alpha$, PPAR $\alpha$ and phospho-Akt increased. The results of this study suggested that FCG pretreatment protected the myocardium from I/R injury by activating Akt and PPAR $\alpha$, decreasing I- $\kappa \mathrm{B} \alpha$ phosphorylation and further repressing NF- $\mathrm{NBp} 65$. However, the results did not confirm that the protective effect of FCG pretreatment against I/R injury in the rat myocardium was exerted by the direct activation of Akt. The activation of Akt can facilitate FCG to activate PPAR $\alpha$ and further inhibit the phosphorylation of $\mathrm{I}-\kappa \mathrm{B} \alpha$ to downregulate the expression and activity of NF- $\kappa \mathrm{Bp} 65$. However, it is not known whether FCG can directly inhibit the expression of NF- $\kappa \mathrm{Bp} 65$ through the interaction of Akt, PPAR $\alpha, \mathrm{I}-\kappa \mathrm{B} \alpha$ and $\mathrm{NF}-\kappa \mathrm{B}$. Further studies are in progress.

In conclusion, we have found and validated that cinnamic acid, glycyrrhizic acid and ferulic acid are present in DGSN decoction, and can be absorbed into the blood of rats following oral administration of DGSN decoction. The optimal drug combination, FCG, is a mixture of glycyrrhizic $(50 \mathrm{mg} / \mathrm{kg})$, cinnamic $(200 \mathrm{mg} / \mathrm{kg})$ and ferulic $(300 \mathrm{mg} / \mathrm{kg})$ acid. FCG was shown to not only lower the content of MDA but also increase the activity of SOD, as demonstrated by the $L 16\left(4^{4}\right)$ orthogonal design. These findings show that FCG may alleviate myocardial I/R injury. It was suggested that FCG acted by significantly decreasing the levels of TNF $\alpha$, IL-1 $\beta$, IL-6 and ICAM-1 in the serum. This significantly decreased the myocardial AAR and IS and alleviated the changes in myocardial tissue construction and cell ultrastructure observed by H\&E staining and transmission electron microscopy. In addition, FCG significantly increased the expression of I- $\kappa \mathrm{B} \alpha$, PPAR $\alpha$ and phospho-Akt, and decreased the expression levels of NF- $\kappa \mathrm{Bp} 65$ and phospho-I- $\kappa \mathrm{B} \alpha$. Accordingly, the results of the present study indicated that the FCG drug combination protected the myocardium from I/R injury through modulation of the Akt, PPAR $\alpha$ and NF- $\kappa$ B pathways.

\section{Acknowledgements}

The authors would like to thank the National Natural Science Foundation of China for partially supporting this study (nos. 30672679 and 81173189).

\section{References}

1. Murray CJ and Lopez AD: Alternative projection of mortality and disability by cause 1990-2020: Global Burden of Disease Study. Lancet 349: 1498-1504, 1997. 
2. Yellon DM and Hausenloy DJ: Myocardial reperfusion injury. N Engl J Med 357: 1121-1135, 2007.

3. Murry CE, Jennings RB and Reimer KA: Preconditioning with ischemia: a delay of lethal cell injury in ischemic myocardium. Circulation 74: 1124-1136, 1986.

4. Philipp S, Yang XM, Cui L, et al: Postconditioning protects rabbit hearts through a protein kinase $\mathrm{C}$-adenosine $\mathrm{A} 2 \mathrm{~b}$ receptor casade. Cardiovasc Res 70: 308-314, 2006.

5. Tissier R, Cohen MV and Downey JM: Protecting the acutely ischemic myocardium beyond reperfusion therapies: are we any closer to realizing the dream of infarct size elimination? Arch Mal Coeur Vaiss 100: 794-802, 2007.

6. Gross ER, Hsu AK and Gross GJ: Opioid-induced cardioprotection occurs via glycogen synthase kinase beta inhibition during reperfusion in intact rat hearts. Circ Res 94: 960-966, 2004.

7. Tissier R, Waintraub X, Couvreur N et al: Pharmacological postconditioning with the phytoestrogen genistein. J Mol Cell Cardiol 42: 79-87, 2007.

8. Efthymiou CA, Mocanu MM and Yellon DM: Atorvastatin and myocardial reperfusion injury: new pleiotropic effect implicating multiple prosurvival signaling. J Cardiovase Pharmacol 45 247-252, 2005.

9. Gao YQ, Zhao GP and Jiang RW: Determination of ferulic acid serum concentration in Danggui Sini Decotion by HPLC and its pharmacokinetics in rats. Zhong Cheng Yao 33: 419-422, 2011 (In Chinese).

10. Gao YQ, Wu J, Jiang RW and Zhao GP: Determination of cinnamic acid and glycyrrhizic acid in rat serum and its pharmacokinetics after oral administration of Dangguisini decoction. Zhong Yao Cai 34: 408-411, 2011 (In Chinese).

11. Zhao X, Gu Y, Song XX, et al: Simultaneous determination of four main components in Dangguisini decoction. Shenyang Yao Ke Da Xue Xue Bao 13: 200-203, 2008 (In Chinese).

12. Nagai T, Egashira T, Yamanaka Y and Kohno M: The protective effect of glycyrrhizin against injury of the liver caused by ischemia-reperfusion. Arch Environ Contam Toxicol 20: 432-436, 1991

13. Abdugafurova MA, Li VS, et al: Antioxidative properties of glycyrrhyzic acid salts and their effect on the liver monooxygenase system. Vopr Med Khim 36: 29-31, 1990 (In Russian).

14. Yokozawa T, Liu ZW and Chen CP: Protective effects of Glycyrrhizae radix extract and its compounds in a renal hypoxia (ischemia)-reoxygenation (reperfusion) model. Phytomedicine 6 : 439-445, 2000.

15. Kilgore KS, Tanhehco EJ, Park JL et al: Reduction of myocardial infarct size in vivo by carbohydrate-based glycomimetics. J Pharmacol Exp Ther 284: 427-435, 1998

16. Nagai T, Egashira T, Kudo Y, Yamanaka Y and Shimada T: Attenuation of dysfunction in the ischemia-reperfused liver by glycyrrhizin. Jpn J Pharmacol 58: 209-218, 1992.

17. Cartron E, Carbonneau MA, et al: Specific antioxidant activity of caffeoyl derivatives and other natural phenolic compounds: LDL protection against oxidation and decrease in the proinflammatory lysophosphatidylcholine production. J Nat Prod 64 480-486, 2001.

18. Banskota AH, Nagaoka T, Sumioka LY, et al: Antiproliferative activity of the Netherlands propolis and its active principles in cancer cell lines. J Ethnopharmacol 80: 67-73, 2002.

19. Neto CC: Cranberry and blueberry: evidence for protective effects against cancer and vascular diseases. Mol Nutr Food Res 51: 652-664, 2007.

20. Huang X, Qin F, Zhang HM, et al: Cardioprotection by Guanxin II in rats with acute myocardial infarction is related to its three compounds. J Ethnopharmacol 121: 268-273, 2009.

21. Yogeeta SK, Raghavendran HR, Gnanapragasam A, et al: Ferulic acid with ascorbic acid synergistically extenuates the mitochondrial dysfunction during beta-adrenergic catecholamine induced cardiotoxicity in rats. Chem Biol Interact 163: 160-169, 2006.

22. Wolfrum S, Richardt G, Dominiak P et al: Apstatin, a selective inhibitor of aminopeptidase $P$, reduces myocardial infarct size by a kinin-dependent pathway. Br J Pharmacol 134: 370-374, 2001.

23. Murota S, Fujita H, Wakabayashi Y and Morita I: Cell adhesion molecule mediates endothelial cell injury caused by activated neutrophils. Keio J Med 45: 207-211, 1996.

24. López-Cacho JM, González-R PL, et al: Robust optimization of alginate-Carbopol 940 bead formulations. ScientificWorldJournal 2012: 605610, 2012.
25. Zhou J, Sun JB, Zheng P, et al: Orthogonal array design for optimization of hollow-fiber-based liquid-phase microextraction combined with high-performance liquid chromatography for study of the pharmacokinetics of magnoflorine in rat plasma. Anal Bioanal Chem 403: 1951-1960, 2012.

26. Xu Y, Zhang Y, Li Y, et al: Growth promotion of Yunnan pine early seedlings in response to foliar application of IAA and IBA. Int J Mol Sci 13: 6507-6520, 2012

27. Cerqueira NF, Hussni CA and Yoshida WB: Pathophysiology of mesenteric ischemia/reperfusion: a review. Acta Cir Bras 20: 336-343, 2005

28. Burley DS, Ferdinandy P and Baxter GF: Cyclic GMP and protein kinase-G in myocardial ischaemia-reperfusion: opportunities and obstacles for survival signaling. Br J Pharmacol 152: 855-869, 2007.

29. Chen HP, Liao ZP, Huang QR and He M: Sodium ferulate attenuates anoxia/reoxygenation-induced calcium overload in neonatal rat cardiomyocytes by NO/cGMP/PKG pathway. Eur J Pharmacol 603: 86-92, 2009

30. Howes MJ, Perry NS and Houghton PJ: Plants with traditional uses and activities, relevant to the management of Alzheimer's disease and other cognitive disorders. Phytother Res 17: 1-18, 2003.

31. Point D, Coudert P, Leal F, et al: Antioxidant activity of some ascorbic and cinnamic acids derivatives. Farmaco 53: 85-88, 1998

32. Jeong HG, You HJ, Park SJ, et al: Hepatoprotective effects of 18beta-glycyrrhetinic acid on carbon tetrachloride-induced liver injury: inhibition of cytochrome P450 2E1 expression. Pharmacol Res 46: 221-227, 2002

33. Jaeschke H: Mechanisms of liver injury. II. Mechanisms of neutrophil-induced liver cell injury during hepatic ischemia-reperfusion and other acute inflammatory conditions. Am J Physiol Gastrointest Liver Physiol 290: G1083-G1088, 2006.

34. Spanos CP, Papaconstantinou P, Spanos P, et al: The effect of $\mathrm{L}$-arginine and aprotinin on intestinal ischemia-reperfusion injury. J Gastrointest Surg 11: 247-255, 2007.

35. Sima N, Lü W and Xie X: Early proteins E6 and E7 of human papillomavirus may attenuate ischemia-reperfusion injury. Med Hypotheses 76: 607-609, 2011.

36. Olanders K, Sun Z, Börjesson A et al: The effect of intestinal ischemia and reperfusion injury on ICAM-1 expression, endothelial barrier function, neutrophil tissue influx, and protease inhibitor levels in rats. Shock 18: 86-92, 2002.

37. Venardos KM, Perkins A, Headrick J and Kaye DM: Myocardial ischemia-reperfusion injury, antioxidant enzyme systems and selenium: a review. Curr Med Chem 14: 1539-1549, 2007

38. Di Paola R, Menegazzi M, Mazzon E, et al: Protective effects of glycyrrhizin in a gut hypoxia (ischemia)-reoxygenation (reperfusion) model. Intensive Care Med 35: 687-697, 2009.

39. Cepinskas G, Rui T and Kvietys PR: Interaction between reactive oxygen metabolites and nitric oxide in oxidant tolerance. Free Radic Biol Med 33: 433-440, 2002.

40. Li C, Browder W and Kao RL: Early activation of transcription factor NF-kappaB during ischemia in perfused rat heart. Am J Physiol 276: H543-H552, 1999.

41. Inoue I, Goto S, Matsunaga T, et al: The ligands/activators for peroxisome proliferator-activated receptor alpha (PPARalpha) and PPARgamma increase $\mathrm{Cu}^{2+}, \mathrm{Zn}^{2+}$-superoxide dismutase and decrease p22phox message expressions in primary endothelial cells. Metabolism 50: 3-11, 2001.

42. Yoo HY, Chang MS and Rho HM: Induction of the rat $\mathrm{Cu} / \mathrm{Zn}$ superoxide dismutase gene through the peroxisome proliferator-responsive element by arachidonic acid. Gene 234: 87-91, 1999.

43. Ding GL, Cheng L, et al: PPARdelta modulates lipopolysaccharide-induced TNFalpha inflammation signaling in cultured cardiomyocytes. J Mol Cell Cardiol 40: 821-828, 2006.

44. Inoue I, Noji S, Awata T, et al: Bezafibrate has an antioxidant effect: peroxisome proliferator-activated receptor alpha is associated with $\mathrm{Cu}^{2+}, \mathrm{Zn}^{2+}$-superoxide dismutase in the liver. Life Sci 63: 135-144, 1998.

45. Marx N, Duez H, Fruchart JC and Staels B: Peroxisome proliferator-activated receptors and atherogenesis: regulators of gene expression in vascular cells. Circ Res 94: 1168-1178, 2004.

46. Marx N, Sukhova GK, et al: PPARalpha activators inhibit cytokine-induced vascular cell adhesion molecule-1 expression in human endothelial cells. Circulation 99: 3125-3131, 1999.

47. Bulhak AA, Jung C, Ostenson CG, et al: PPARalpha activation protects the type 2 diabetic myocardium against ischemia-reperfusion injury: involvement of the PI3-Kinase/Akt and NO pathway. Am J Physiol Heart Circ Physiol 296: H719-H727, 2009. 